\title{
Use of misoprostol for termination of second and third trimester pregnancy with intrauterine foetal death
}

\author{
Sonal Palod $^{1}$, Trupti Nayak ${ }^{2}$ \\ ${ }^{1}$ Department of Obstetrics \& Gynaecology, PDU Medical College, Rajkot, Gujarat, India \\ ${ }^{2}$ Department of Obstetrics \& Gynaecology, MP Shah Medical College, Jamnagar, Gujarat, India
}

Received: 19 February 2016

Revised: 22 February 2016

Accepted: 12 March 2016

\section{*Correspondence:}

Dr. Sonal Palod,

E-mail: drsonal1234@gmail.com

Copyright: $\odot$ the author(s), publisher and licensee Medip Academy. This is an open-access article distributed under the terms of the Creative Commons Attribution Non-Commercial License, which permits unrestricted non-commercial use, distribution, and reproduction in any medium, provided the original work is properly cited.

\section{ABSTRACT}

Background: Prostaglandins (PGs) is an alternative method for induction of labour in women with intrauterine foetal death (IUFD). The vaginal route is advantageous because slow peak levels, sustained for long time and fewer side effects. So this study was aimed to investigate the effectiveness of misoprostol in the induction of labour and abortion in $2^{\text {nd }}$ and $3^{\text {rd }}$ trimester pregnancies associated with IUFD. The objective of the study was to assess the efficacy of misoprostol in fixed dosage schedule for the termination of pregnancy in IUFD and to evaluate induction delivery interval with misoprostol.

Methods: A prospective study was conducted in department of Obstetrics \& Gynaecology in tertiary care centre. Inclusion criteria included women of II or III trimester of pregnancy with IUFD. Singleton pregnancy with longitudinal lie in non-scarred uterus with confirmed intrauterine fetal death with bishop score $<6$. Exclusion criteria included multiple pregnancy, lie other than longitudinal, scarred uterus, hypersensitivity to misoprostol, Bishop score more than 6. Permission from IEC and written informed consent was taken before study participation. Complete examination and investigation of patient was done and induction with misoprostol was done as per dosage schedule mentioned by WHO Bellago, Italy (Feb 2007). Patient was intensively monitored intraoperatively and postoperatively. Follow-up was done till 15 days postpartum.

Results: Out of 107 cases, majority cases were of 22-28 week gestation. Maximum cases (57\%) were of age group 21-25years. Induction succeeded in 92 cases with mean induction delivery interval of 13.2 hours. $50 \%$ cases had favorable cervix with mean induction delivery interval 9.4 hours and rest had 16.53 hours ID interval with mean ID interval 13.67hours. Complete exclusion was seen in 92 cases (85.98\%) and incomplete in 10 cases which required check curettage. Failure of method was seen in 5 cases $(4.67 \%)$ which were terminated by alternative methods. Most common side effect was abdominal cramp (9.3\%) and nausea (5.6\%).

Conclusions: Vaginal misoprostol is safe and effective in termination of second and third trimester pregnancy in case of intrauterine fetal death.

Keywords: IUFD, Misoprostol, Cervical ripening, Induction delivery interval.

\section{INTRODUCTION}

A woman may need to give birth prior to the spontaneous onset of labour in situations where the fetus has died in utero (also called a stillbirth), or for the termination of pregnancy where the fetus, if born alive, would not survive or would have significant disability. This situation is psychologically stressful for the woman, her partner and family and for the health professionals caring for her.

The management of IUFD poses a dilemma. Although a significant number of these patients will spontaneously go into labour within several weeks, many do not. 
Moreover, after the diagnosis, the social pressures and emotional aspects of delivery are usually considerable, and the medical consequences of postponing delivery can be significant. Within the past two decades, Prostaglandins (PGs) have provided an alternative method for induction of labour in women with IUFD. ${ }^{1,2} \mathrm{~A}$ large body of evidence exists that shows that the use of Misoprostol for labour induction is highly efficacious and safe. ${ }^{3}$ Misoprostol is absorbed rapidly when administered orally, vaginally, rectally or intracervically. The vaginal route is advantageous because peak levels are reached slowly and sustained for a long time and this is associated with fewer side effects. ${ }^{3,4}$ The vaginal route is also more effective than the oral route. ${ }^{5-8}$ The greater bioavailability of vaginal Misoprostol probably explains the clinical results.

The advantage of using misoprostol for induction of labour and abortion over conventional oxytocic is overwhelming. Firstly it is a stable analogue of prostaglandin $\mathrm{E}_{1}$ and thus less subjected to strict storage rules - an obvious advantage in tropical climate. Secondly, it is cheap and widely available and thirdly, in addition to intravaginal administration, it can be taken orally. These advantages make Misoprostol a favourable agent in our environment where conventional prostaglandin $\mathrm{E}_{2}$ is not only scarce but prohibitively expensive. So the aim of this study is to investigate the effectiveness of misoprostol in the induction of labour and abortion in $2^{\text {nd }}$ and $3^{\text {rd }}$ trimester pregnancies associated with intrauterine foetal death.

\section{METHODS}

This was a prospective study carried out from April 2011 to August 2012 at Department of Obstetrics \& Gynecology, M. P. Shah Government Medical College, Jamnagar, Gujarat.

\section{Inclusion criteria}

Women of II or III trimester of pregnancy with IUFD. Singleton pregnancy with longitudinal lie in non-scarred uterus with confirmed intrauterine fetal death with bishop score $<6$.

\section{Exclusion criteria}

Multiple pregnancy, lie other than longitudinal, scarred uterus, hypersensitivity to misoprostol, bishop score more than 6. All women met with inclusion criteria, gave informed written consent for participated in the study.

\section{After admission}

Complete history of the patient including her name, age, caste, residence, socio-economic status, educational status, obstetric \& menstrual history were noted and history of previous uterine surgery was especially asked for. Any medical or surgical illness or drug hypersensitivity were ruled out. Specific past, personal \& family history was enquired about. Thorough physical general \& systemic examination was carried out. Gestational age was determined from date of last menstrual period and abdominal examination findings followed by ultrasonography. After per-abdomen examination for determining gestational age and looking for any abdominal scar etc. local examination was done to rule out any local genital infection \& cervical anomaly. This was followed by per vaginal examination for cervical length, condition of external OS.

Investigations like $\mathrm{Hb}$, Blood grouping with $\mathrm{Rh}$ typing, urine for albumin \& sugar, BT/CT, RPR, Antibody test for HIV(after pretest counselling) were done in all cases. In select-requisite cases, RBS, LFT, RFT coagulation profile are also requested. Ultrasonography was done in all cases to determine gestational age, placental localization, fetal cardiac motion localization, AFI and any congenital anomaly of fetus

\section{Methods for termination}

After this, written informed consent of the women was taken (consent of guardian taken if the women are minor or mentally ill) explaining her condition (IUFD), methods available for termination, details of the procedure to be performed possible complications \& their treatment, chances of failure and ways out.

\section{Dose schedule to participants}

Women received Misoprostol in multiple doses as per guidelines of WHO clinical guidelines Bellagio, Italy (Feb 2007).

- 13 - 17 wks: 200mcg Misoprostol PV x 6 hrly max 4 doses.

- 18 - 26 wks: 100 mcg Misoprostol PV x 4-6 hrly max 4 doses.

- $>26$ wks: 25 - 50 mcg misoprostol 4 hrly, $\max 6$ doses.

Failure of procedure is defined as failed expulsion of fetus at 24 hours or the occurrence of systemic adverse signs and symptoms severe enough to prohibit further use of the drug.

\section{Examination}

Vital signs i.e. T, P, BP, RR were monitored every 4 hours. Occurrence of fever, chest pain, breathing difficulty, vomiting, diarrhoea and signs of water intoxication was recorded and treated accordingly. Once having labor established, she was offered intrapartum care as per protocol for "Active management of First stage of labour" and "Active management of Second stage of labour" as and when required. P/V examination was repeated every 6 hours for re-assessment. After 
expulsion of fetus and placenta, fetus was examined for weight, sex \& anomaly and placenta for weight, completeness and length of the cord. If required, $\mathrm{P} / \mathrm{S}$ to rule out cervical injury was done followed by $\mathrm{P} / \mathrm{V}$ to rule out incomplete abortion. Post expulsion sonography was done as and when required.

Completeness of abortion is defined as expulsion of both placenta and fetus without further need of Suction and Evacuation. The induction/abortion - delivery interval is defined as time of administration of $1^{\text {st }}$ dose of Misoprostol to delivery/abortion.

\section{After delivery}

Antibiotic in form of Cap. Ampicillin (500mg) 6 hourly for total of 5 days was given to all patients Inj. Anti-D $150 \mathrm{mcg}$ IM was given to $\mathrm{Rh}$ negative mother. One tablet of cabergolin $50 \mathrm{mcg}$ was given stat in case of pregnancy less than 28 wks, and two tablets stat were given in pregnancy more than 28 wks for inhibiting breast milk synthesis. Postpartum counselling was done in all women especially regarding contraception, including bereavement counselling.

\section{Follow up}

Requisite follow up was maintained and patient was called on $3^{\text {rd }}, 7^{\text {th }}$ day and then $15^{\text {th }}$ day. Any significant complains like fever, abdominal pain or bleeding $\mathrm{P} / \mathrm{V}$ was asked for. P/S, P/V examination was done. Post abortal advice including contraception and nutrition was provided.

\section{RESULTS}

There were 107 patients participated in study with means age of $24.61 \mathrm{yr} \pm 4.38$ year. 52 patients $(49 \%)$ were of second trimester and 55 patients $(51 \%)$ were of third trimester. 56 patients were of rural population and 51pts were of urban population. 56 patients were illiterate and 51 patients were literate. The mean age of the study group was $24.61 \mathrm{yr}$ and the mean I.D interval was $13.20 \mathrm{hr}$.

Table 1: Age wise distribution of patients and variation in induction delivery interval (ID Interval).

\begin{tabular}{|llll|}
\hline $\begin{array}{l}\text { Age } \\
\text { (years) }\end{array}$ & $\begin{array}{l}\text { No .of } \\
\text { cases }\end{array}$ & Percentage & $\begin{array}{l}\text { Mean I.D } \\
\text { interval } \\
\text { (hrs) }\end{array}$ \\
\hline$<20$ & 17 & 15.88 & 13.38 \\
\hline $21-25$ & 61 & 57.01 & 13.59 \\
\hline $26-30$ & 20 & 18.71 & 11.82 \\
\hline$>31$ & 9 & 08.40 & 13.33 \\
\hline
\end{tabular}

The mean age of the study group was $24.61 \mathrm{yr}$ and the mean I.D interval was $13.20 \mathrm{hr}$.
Table 2: Parity wise distribution of patients and their variation in induction delivery interval.

\begin{tabular}{|lll|}
\hline Parity & No. of cases & $\begin{array}{l}\text { Mean I.D. } \\
\text { interval (hrs) }\end{array}$ \\
\hline Primi & 46 & 13.5 \\
\hline Second gravida & 29 & 12.43 \\
\hline Third gravida & 20 & 12.3 \\
\hline Multigravida & 12 & 15.45 \\
\hline
\end{tabular}

Out of 107 cases, 50pts had favourable cervix and mean I.D. interval in this population was $9.41 \mathrm{hr}$. In rest 57 cases cervix was not favourable and mean I.D. interval in this population was $16.53 \mathrm{hrs}$.

In our study group 18patients belonged to $13-17 \mathrm{wk}$ gestation, the mean I.D. interval of this group was $14.25 \mathrm{hr}$. There were $23 \mathrm{pts}$ in $18-21 \mathrm{wk}$ gestation group, the mean I.D. interval of this group was $16.34 \mathrm{hrs}$. There were $34 \mathrm{pts}$ in $22-28 \mathrm{wk}$ gestation group, the mean I.D, interval of this group was $13.67 \mathrm{hr}$. The rest $32 \mathrm{pts}$ belonged to those with gestational age > 28wks. The mean I.D. interval in this group was $9.859 \mathrm{hr}$.

In our study group, there were 36pts with uterine size between 14-20wk size and their mean I.D. interval was $15.23 \mathrm{hr}$. There were $45 \mathrm{pts}$ with uterine size between $22-$ $28 \mathrm{wk}$ and their mean I.D. interval was $13.48 \mathrm{hrs}$. There were $26 \mathrm{pts}$ with $>28 \mathrm{wk}$ uterine size and their mean I.D. interval was $9.23 \mathrm{hr}$.

Table 3: Mean induction delivery interval in cases according to cause of intrauterine fetal death.

\begin{tabular}{|lll|}
\hline Causes of IUFD & No. of cases & $\begin{array}{l}\text { Mean I.D } \\
\text { interval } \\
\text { (hrs) }\end{array}$ \\
\hline Abruptio placenta & 07 & 10.64 \\
\hline $\begin{array}{l}\text { PET/eclampsia/Chr. } \\
\text { HT }\end{array}$ & 18 & 12.75 \\
\hline Anaemia & 03 & 15.33 \\
\hline Anomaly & 12 & 20.62 \\
\hline Sepsis & 19 & 13.05 \\
\hline $\begin{array}{l}\text { Oligo/meconium/post- } \\
\text { term pregnancy }\end{array}$ & 05 & 10.8 \\
\hline Rh incompatibility & 04 & 22.16 \\
\hline PROM & 05 & 09.2 \\
\hline Cord pathology & 03 & 12.5 \\
\hline Trauma & 02 & 12 \\
\hline Idiopathic & 29 & 10.98 \\
\hline
\end{tabular}

In our study group, out of 107 cases, 92patients had a complete expulsion without any evidence of retained products and within $24 \mathrm{hrs}$. This means that $85-98 \%$ cases had successful outcome. 10 cases i.e., 9.34\% cases had expulsion of fetus within $24 \mathrm{hrs}$ but had retained placenta for which check curettage was done. In remaining 5 $(4.67 \%)$ case I.D. interval extended to be more than $24 \mathrm{hr}$ 
and additional help with Foleys catheter or betadine saline induction or hysterectomy were done.

Table 4: Outcome of cases.

\begin{tabular}{|lll|}
\hline Outcome & No of cases & Percentage \\
\hline Complete expulsion & 92 & 85.98 \\
\hline Incomplete expulsion & 10 & 9.34 \\
\hline Failure(>24 hrs) & 5 & 4.67 \\
\hline
\end{tabular}

Table 5: Cumulative I.D. interval in the study population

\begin{tabular}{|lll|}
\hline I.D interval & No of cases & Percentage \\
\hline Within 12 hrs & 61 & 57.0 \\
\hline 12-24 hrs & 41 & 38.31 \\
\hline >24 hrs & 5 & 4.67 \\
\hline
\end{tabular}

In our study population, 61 cases i.e., $57.0 \%$ cases delivered within $12 \mathrm{hrs}$. $38.31 \%$ cases i.e. 41 patients delivered within 12-24 hrs. Only $4.67 \%$ (5 cases) cases couldn't deliver in $24 \mathrm{hrs}$ and had to be given added augmentation.

Most common side effect due to misoprostol was cramping abdominal pain seen in 10 cases i.e., 9.3\%. 6pts i.e., $5.6 \%$ had nausea and 5 patients had fever. Diarrhoea chills and rashes were noted in 2 pts each. There was no any incidence of hemorrhage, injury, or any maternal death.

Out of 107 cases, induction of labour succeeded in 92 cases with mean induction delivery of 13.20 hours. The mean age of our study group was 24.61 years with $49 \%$ were from urban area and 54\% were from rural area. 56 patients were illiterate and 51 patients were literate. 63 patients had taken antenatal care and 44 had not taken antenatal care. 76 were from lower socioeconomic class. Maximum cases were of 21-25 year age group i.e. 57\% with mean induction delivery interval 13.59 hours. There were 50 cases with favourable cervix with mean induction delivery interval of $9.41 \mathrm{hrs}$ and 57 cases were with unfavourable cervix with mean induction delivery interval of 16.53 hours.

According to weeks of gestation maximum cases were of 22-28 week gestation with mean induction delivery interval 13.67 hours. According to uterine size on admission, maximum cases were of $22-28$ weeks uterus i.e. 45 cases with mean induction delivery interval 13.48 hours. Most common cause of intrauterine fetal death in our study was idiopathic followed by sepsis followed by PIH. Complete expulsion was seen in 92 cases $(85.98 \%)$ and incomplete in 10 cases which required check curettage. Failure of method was seen in 5 cases i.e. 4.67\%.Most common side effect seen in our study was cramping abdominal pain $(9.3 \%)$ followed by Nausea in $(5.6 \%)$.

\section{DISCUSSION}

The occurrence of IUFD constitutes a major nightmare to women and attending clinicians. It is even more agonizing with a feeling of defeat to clinician if it occurs unexpectedly and the cause cannot be explained. Therefore, the ideal drug for termination of pregnancy in cases of IUFD should not only be effective and safe but should be affordable to avoid additional financial burden arising from a wasted pregnancy.

Our experience shows that misoprostol is a very effective and safe method of induction in IUFD with almost $100 \%$ vaginal delivery rate and few complications. Its stability at room temperature need for no special storage requirement and cost effectiveness make it an ideal method of induction in both developing and developed countries. The result of this study is similar to the findings in other reports.

In our study IUFD is most common in 21 to 30 year age group i.e $\approx 57 \%$ which is similar to the study by M.O. Elmahaish et al and Jahanfar SH et al. ${ }^{9,10}$ In our study nearly $42 \%$ patients were primipara which is almost similar to the study by Jahanfar $\mathrm{SH}$ et al in which the incidence of IUFD in primipara was $39.2 \%$. $^{9}$

Among all the studies conducted, it was noted that those with favourable cevix always had lesser induction delivery intervalIn our study nearly $46.7 \%$ patients had favourable cervix and hence had lesser mean induction delivery interval i.e. 9.41 hours. While $55.3 \%$ patients had unfavourable cervix and their induction delivery interval was more. This is clearly explained by the fact that those with favourable cervix were already in labour and hence actually needed only augmentation with misoprostol to clear the latent phase of labour. ${ }^{11}$ In our study the mean induction delivery interval is gradually decreasing with increase in weeks of gestation.this is because of increase in the receptor density in uterus as well as increase in sensitivity of uterus to the oxytocis as the pregnancy progresses (williams $23^{\text {rd }}$ edition).

In our study the mean induction delivery interval (ID interval) of 14-20 wk uterine size is 15.23 hours which is almost similar to that in Abdul et al study. ${ }^{12}$ In our study group the most common cause of IUFD was idiopathic which is similar to Abdul et al study. ${ }^{12}$ the second most common cause of IUFD in our study was infection which was similar to Ezechi et al study. ${ }^{13}$

In our study group $85 \%$ cases had complete expulsion and about $10 \%$ had retained products while in study of Gomez et al 25\% cases had retained products. ${ }^{14}$

In our study $85.9 \%$ females delivered within 24 hours which is similar to Gomez et al study. ${ }^{14}$ In our study nearly $5 \%$ cases delivered in $>24 \mathrm{hrs}$ and needed extra augmentation while in Gomez et al study $15 \%$ cases required $>24$ hrs to deliver and/or extra augmentation. ${ }^{14}$ 
The most common side effects seen in our study were fever followed by diarrhoea which is similar to El Garib et al study. ${ }^{15}$

\section{CONCLUSIONS}

Results of our study suggest that vaginal misoprostol is safe and effective in termination of second and third trimester pregnancy in case of intra uterine fetal death. It is associated with very low frequency of side effects and also cost effective which indirectly increases patient compliance.

\section{Funding: Not required}

Conflict of interest: None declared

Ethical approval: The study was approved by the Institutional Ethics Committee

\section{REFERENCES}

1. Centers for Disease Control and Prevention, National Center for Health Statistics Web site; Belkin and Wilder, 2007.

2. Kochenour NK. Management of fetal demise. Clin. Obstet.Gynecol. 1987;30:322.

3. Hale RW, Zinberg S. Use of Misoprostol in Pregnancy. New England J. Med. 2001;344:59-60.

4. Gottschall D, Borgida A, Mihalek J, Sauer F, Rodis I. A randomized clinical trial comparing Misoprostol with prostaglandin E2 gel for pre induction cervical ripening. Am J ObstetGynecol. 1997;177:1067.

5. Ho PC, Ngai SW, Liu KL, Wong GC, Lee SW. Vaginal Misoprostol compared with oral misoprostol in termination of second trimester pregnancy. Obstet Gynecol. 1997;90(5):735-8.

6. Ngai SW, Chan YM, Lam SW, Lao TT. Labour charateristics and uterine activity: Misoprostol compared with oxytocin in female at term with pre labour rupture of membranes. Br J Obstet Gynecol. 2002; 107:222.

7. Bartley J, Baird DT. A randomized study of Misoprostol and gemeprost in combination with mifepristone for induction of abortion in the secondtrimester of pregnancy. $\mathrm{Br} \mathrm{J}$ Obstet Gynaecol. 2002;109:1290-4.

8. Bebbington MW, Kent N, Lim K, Gagnon A, Delisle MF, Tessier F. A randomized trial comparing two protocols for the use of Misoprostol in mid trimester pregnancy termination. Am J Obstet Gynecol. 2002;187:853-7.

9. Jahanfar SH, Ghiyasi P, Haghani H. Risk factors related to intra uterine fetal death in Iran, A casecontrol study. Shiraz E-Medical Journal. 2005;6(3 \& 4).

10. Elmahaish MO, Asherkaci HM, Elsraiti OA. Epidemiology of ante-partum intra uterine fetal death. Al-satil journal. P: 37-42.

11. Dutta DC. Text book of obstetrics and gynecology. page no 322.

12. Abdul MA, Shittu SO, Ameh N. Effectiveness of Misoprostol in the Management of Intra-Uterine Foetal Death. Annals of African Medicine. 2006;5(4):174-7.

13. Ezechi OC, Ndububa VI, Nwokoro CA. Induction of labour by vaginal misoprostol for Intra Uterine Fetal Death. J Obstet Gynecol Ind. 2004;54(6):561-3.

14. Gomez ponce de leone R, Wing D, Fiala C. Misoprostol for Intra Uterine Fetal Death. International Journal of Obstretics and Gynecology. 2007;99:S190-3.

15. EL-Gharib MN, Elebyary MT. Vagiprost in management of second and third trimester intrauterine fetal death. Medical Practice and Review. 2011;2(2):16-22.

Cite this article as: Palod S, Nayak T. Use of misoprostol for termination of second and third trimester pregnancy with intrauterine foetal death. Int J Reprod Contracept Obstet Gynecol 2016;5:121620. 